\title{
OECD/DAC ENVIRONET(환경과 개발 네트워크)의 전략적 환경평가 활동 현황
}

박 희 수 KOICA 기후변화환경1팀 연구관

목차
। . 서론
II. SEA의 기본 개념과 주요 이슈
II. 환경과 개발 네트워크(ENVIRONET)의 SEA 관련
활동현황
IV. 결론

주제어: ENVIRONET, 전략적 환경평가, 기후변화, 환경 주류화

\section{I. 서론}

개발로 인한 환경훼손 사례가 발생하고 파괴된 환경으로 인하여 경제성장이 지연되는 결과들이 누 적되면서 환경을 활용하고 관리하는 방식이 장기적인 발전에 미치는 중요성이 인식되기 시작하였 다. 특히 개발도상국의 경우 주민들은 그들의 생계를 토지, 산림, 물 등 자연자원에 크게 의존하며 또한 자연자원이 파괴될 때 가장 먼저 피해를 입기에 올바른 환경 관리는 모든 개발협력에서 경제 적, 사회적 이슈만큼 중요하다는 의식이 세계적으로 공유되기 시작하였다.

선진원조기관들은 개별적인 프로젝트 사업에서 환경적인 요소를 고려하는 환경영향평가 (Environmental Impact Assessment, EIA)를 수행하여 왔으나 곧 EIA가 환경이 받는 누적효 과, 간접적 영향 등을 제대로 고려하지 못하고 생물다양성 손실, 오존층 파괴 및 기후변화와 같 
은 인류의 생존을 위협하는 전지구적인 이슈에 제대로 대처하지 못한다는 사실을 깨닫게 되었다 (Borysova, 2007). 더욱이 공여국들이 원조효과를 높이고 수원국의 지속가능한 개발을 달성하기 위해 일회성 사업이 아닌 보다 상위수준인 전략 및 정책 수립 단계에서 개발협력을 진행하면서 환 경적인 고려 또한 이러한 변화된 상황을 반영하고 $\mathrm{EIA}$ 와 같은 기존의 정책적 도구를 보완할 필요가 발생하였다(박명지, 2009). 전략적 환경평가(Strategic Environmental Assessment, SEA)는 이 러한 맥락에서 개발된 것으로 90년대 중반부터 관심이 급증하였으며 이어서 유럽지역에서 국가 수 준에서 SEA를 활용하는 경험이 축적되기 시작하였다.

$\mathrm{SEA}$ 는 2005년 채택된 원조효과에 관한 파리선언에 포함되면서 더욱 주목을 받고 있다. 원조의 효 과성 제고를 위한 5 가지 핵심 원칙을 제시하는 파리선언은 환경 평가에서 조화된 접근 방식의 사용 을 촉진하며 이를 위해 공여국과 수원국 모두 “섹터와 국가 레벨에서 SEA를 위한 공통된 접근법을 개발하고 응용”하기 위한 노력을 추구해야 함을 명시하였다(OECD, 2005).

$\mathrm{OECD}$ 에서 개발협력을 담당하고 있는 $\mathrm{DAC}$ 은 앞서 말한 환경과 개발의 연관성에 대해 집중해왔으 며 환경적인 고려를 개발협력 프로그램에 접목하는 도구와 방식을 연구해왔다. DAC의 세부적인 작 업의 대부분은 주제별로 특화된 작업부서(working parties)와 네트워크를 통해 이루어지는데 개발 과 환경에 대한 논의는 이러한 네트워크 중의 하나인 환경과 개발 네트워크(ENVIRONET, 정식 명 칭은 Network on Environment and Development Co-operation)가 담당하고 있다. 환경과 개 발 네트워크는 2004년 SEA를 위한 작업반을 설립하고 SEA의 사용 확대를 위해 꾸준히 노력해오 고 있다.

우리나라는 ‘전략적 환경평가'와 '전략환경평가', 그리고 '전략환경영향평가’라는 용어가 혼용되어 사용될 정도로 아직 SEA가 확고히 자리 잡지 못한 상황으로 $\mathrm{DAC}$ 가입에 발맞추어 환경을 주류화 하고 원조효과성을 제고하기 위한 국제적인 추세를 파악하는 등 역량강화를 위해 더욱 노력해야하 는 상황이다. 이에 본고에서는 $\mathrm{SEA}$ 의 개념과 성공적인 $\mathrm{SEA}$ 의 특징, 주요 이슈들을 간략히 살펴보 고 $\mathrm{SEA}$ 를 중심으로 환경과 개발 네트워크의 역할과 주요 성과를 소개하고자 한다. 


\section{SEA의 기본 개념과 주요 이슈}

\section{SEA 관련 주요 개념 및 요소}

$\mathrm{OECD} \mathrm{DAC}$ 은 $\mathrm{SEA}$ 작업반이 2년여에 걸쳐 작성한 ' $\mathrm{SEA}$ 적용을 위한 정책 지침(DAC Policy Guidance on Applying Strategic Environmental Assessment, 이하 SEA 정책지침)'을 통 해 SEA를 "환경적인 고려를 의사결정의 상위단계인 정책, 계획, 프로그램(Policy, Plan, and Program, $\mathrm{PPP}$ ) 수준에서부터 통합하고, 경제적 · 사회적 요소와의 상관관계를 평가하기 위한 분 석적이며 참여적인 접근 방식”으로 정의하였다 $(\mathrm{OECD}, 2006)$. 세계은행의 환경전문가인 David Hanrahan은 SEA에서 'strategic'의 뜻을 “정책 결정과정에서 중요 의사 결정에 상당한 영향을 미 칠 수 있도록 충분히 일찍 발생하는 것” 으로 설명하였다. ${ }^{1)}$ 이에 비추어 SEA의 가장 큰 특징은 특 정 프로젝트가 환경에 미치는 영향을 분석하고 대안을 제시하는 EIA와는 달리, 개별 프로젝트, 그 리고 $\mathrm{PPP}$ 로 구성되는 정책 결정의 피라미드에서 환경적인 고려가 충분히 사전에 반영되어 지속가 능성을 주류화하는 것이라 할 수 있다.

$\mathrm{SEA}$ 는 하나의 또는 고정된 방식이 아니라 다양한 방법을 사용하는 복합적인 접근방식으로 $\mathrm{OECD}$ $\mathrm{DAC}$ 은 설명하고 있으며 다른 문헌들도 이와 유사한 주장을 펼치고 있다(Ahmed 등, 2005). 성공 적인 $\mathrm{SEA}$ 는 그것이 적용되는 대상 또는 상황에 맞추어서 보완되고 변형되어야 하며 이것을 다른 방식으로 표현하면 경제적, 사회적 고려와 병행하여 환경적인 고려가 반드시 반영되도록 보장하는 것을 넘어서서 경제적, 사회적, 환경적 요소가 서로 통합되어 평가되고 상호연관성이 강조되는 방 식으로 추진되는 것을 의미한다. 이와 같은 상호연관성을 〈그림 1)에 나타내었다.

1) http://info.worldbank.org/etools/docs/library/121368/m1_harahan.pdf 


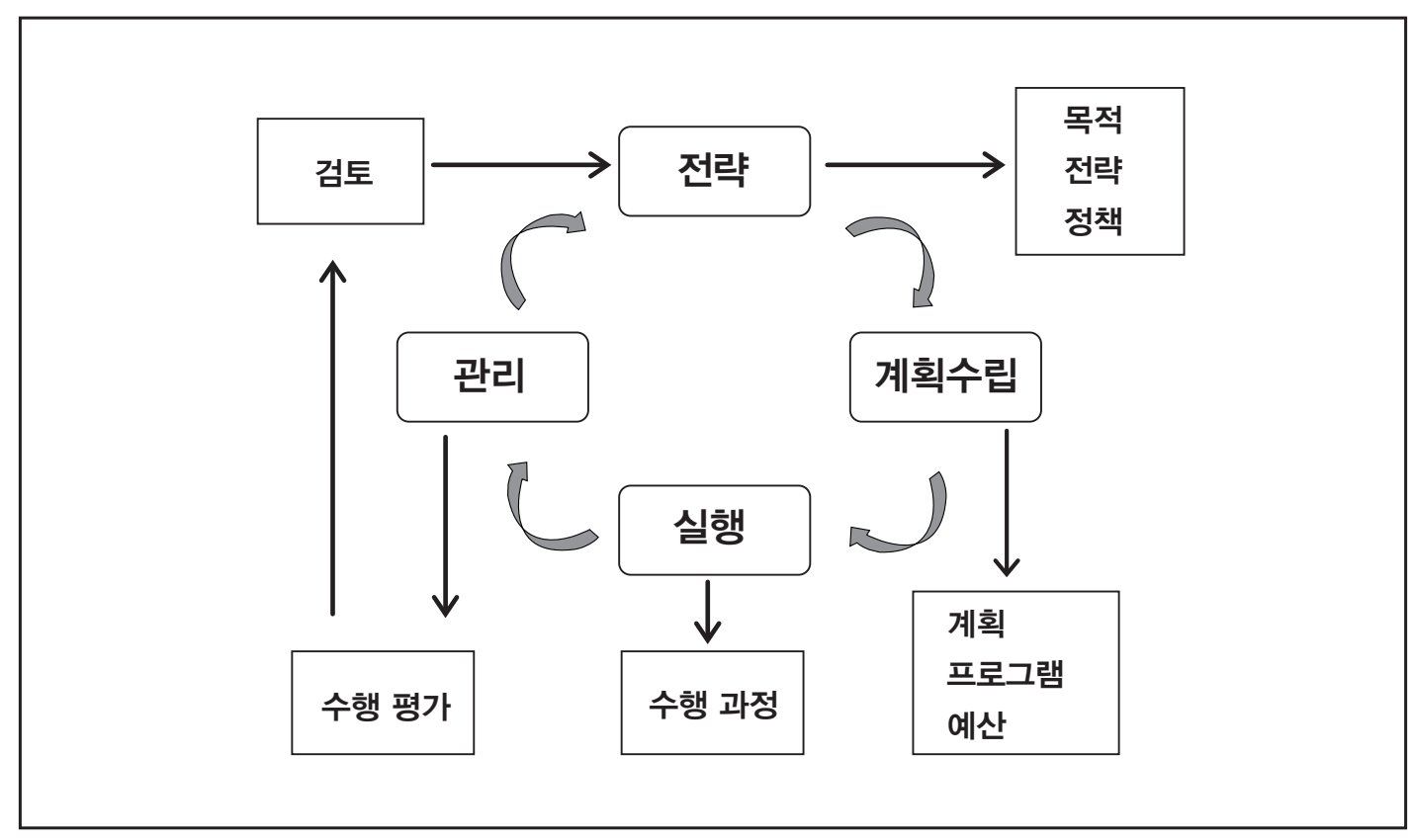

$\mathrm{DAC}$ 의 SEA 정책지침은 $\mathrm{SEA}$ 가 만족시켜야 하는 기본적인 원칙으로 명확한 목표를 설정하고, 기존 의 정책 및 계획과 통합되며, 제안된 $\mathrm{PPP}$ 및 대안들의 잠재적인 효과와 위험을 분석하고, 선호하는 안에 대한 정당성을 제공하며, 환경적 - 경제적 - 사회적 고려사항들 간의 연결고리 등을 제시하고, 주요 이해관계자를 파악하며, 효과적인 품질 관리 방식을 포함하고, 진행과정의 투명성과 비용효율 성을 제고하며, 완료 후에 공식적인 사후평가를 실시하고, 해당 $\mathrm{PPP}$ 의 결과를 모니터하는 것 등을 제시하였다.

여러 국가들과 기관들이 구축한 $\mathrm{SEA}$ 관련 경험을 바탕으로 $\mathrm{SEA}$ 작업반은 성공적인 $\mathrm{SEA}$ 활용을 위해〈그림 2〉와 같은 4 개의 기본단계를 보여주었다. 각각의 단계는 보다 더 세분화된 활동단계로 나뉠 수 있으나 이것들이 반드시 명기된 순서대로 행하여질 필요는 없다고 SEA 정책지침은 설명하 고 있다 (OECD, 2006).

2) 출처: Partidario, 2006 


\section{SEA 적용 배경 수립}

- 심사

· 목적 설정

· 이해관계자 규명

\section{SEA 수행}

· 이해관계자와의 대화를 통한 범위 결정

· 기준선 확정을 위한 자료수집

- 대안규명

· 기회 및 영향 완화 방법 규명

· 품질 관리

- 보고

\section{3. 정책결정보고와 영향}

- 이해관계자와의 대화를 통한 권고 제안

\section{4. 모니터링 및 평가}

- PPP의 결정과정 모니터링

- PPP의 실행 모니터링

· SEA 및 PPP 전체평가

개별 프로젝트 형태에서 프로그램이나 정책 분야를 지원하는 것으로 개발협력의 무게가 이동한 것 은 SEA가 투입될 수 있는 많은 적용시점(entry points)을 제공한다. SEA 정책지침은 개발협력에 서 효과적인 $\mathrm{SEA}$ 적용을 위한 12 개의 적용시점을 제시하였다. 〈표 1〉에서와 같이 12 개의 적용시 점은 (1)개도국이 주도하는 전략적 계획 수립 과정, (2) 공여기관 자체의 추진 절차, (3) 관련된 기 타 상황으로 분류될 수 있다. SEA 가이던스는 각가의 적용시점에서 다뤄져야할 주요 질문들과 체 크리스트도 포함하였다. 


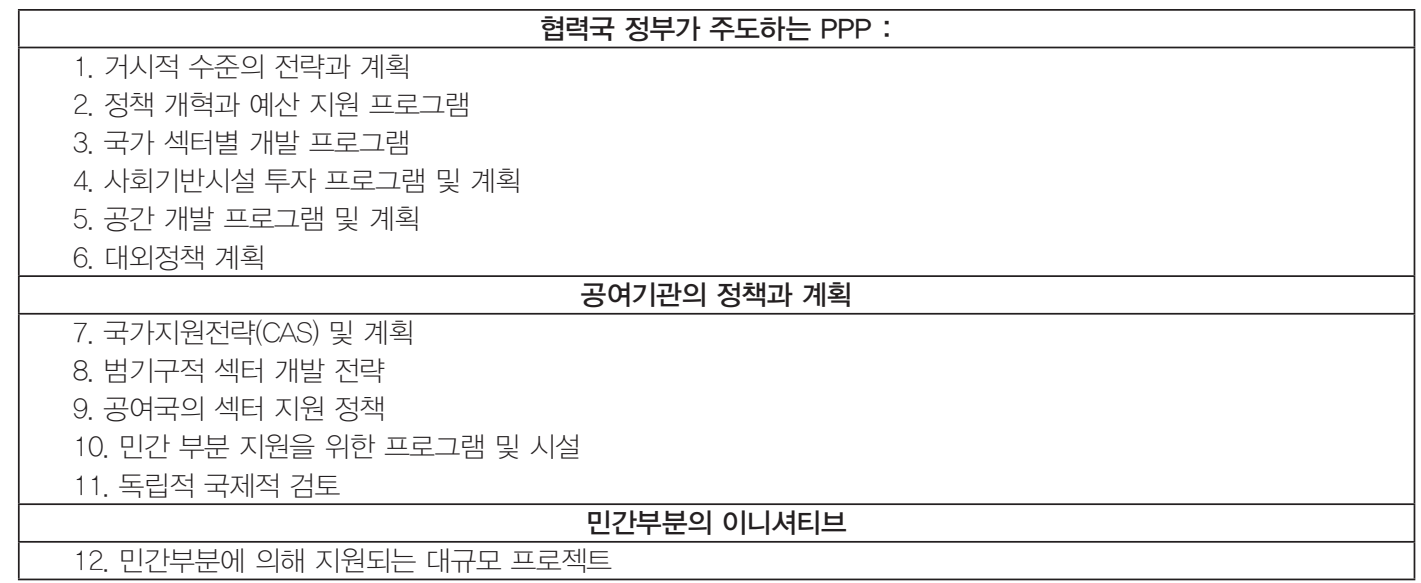

\section{SEA를 통합한 다자개발은행의 프로그램 주기}

대부분의 다자개발은행(Multilateral Development Banks, MDB)들은 환경적인 고려를 개발협력 에 통합시키는 시도를 해왔으며 특히 세계은행은 SEA에 대한 실험적 성격의 프로젝트를 아시아와 라틴아메리카 지역에서 1990년대부터 시작하여 왔다.

〈그림 3〉는 세계은행과 아시아개발은행의 프로그램 운영 주기에 기초하여 환경적인 고려가 없는 $\mathrm{MDB}$ 의 프로그램 실행 단계를 나타낸 것이다. $\mathrm{MDB}$ 직원, 타공여기관, 수원국 정부 등으로부터 정 책적인 의견 수렴을 통해 국가지원전략(Country Assistance Strategy, CAS) 초안이 만들어지며 그 후 내외부적으로 협의 및 조정을 거쳐 거시적인 경제 및 산업부분에 초점을 맞춘 최종 CAS가 탄 생하게 된다. 


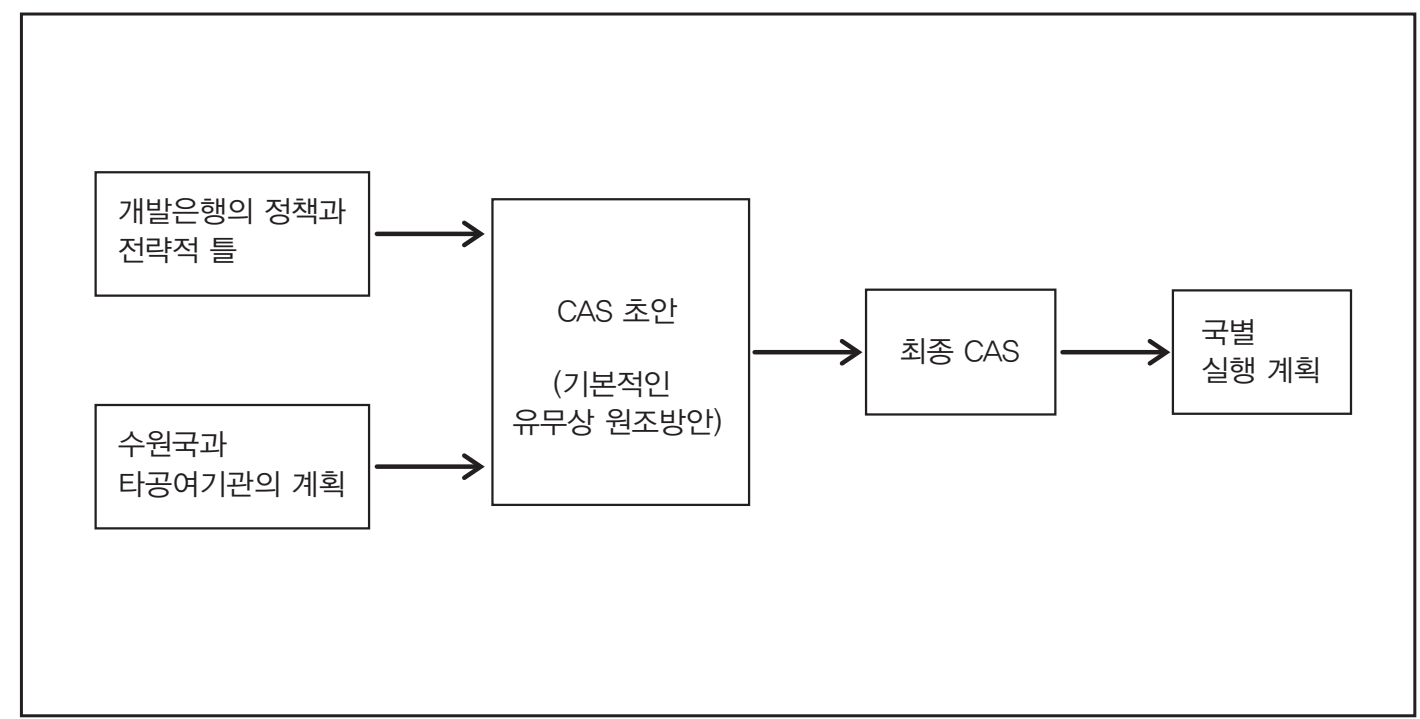

앞서 말했듯이 주요 $\mathrm{MDB}$ 는 이미 환경적인 고려를 통합하는 시도를 하여왔으나 Annadale 등은 그 간의 시도에서 환경적인 요소들이 분절적으로 다루어져 왔음을 비판하며 SEA 활용에 대한 포괄적 이며 연관성이 높은 접근법을 제시하였다(Annadale 등, 2001). 그들이 제안한 새로운 프로그램의 주기는 정책에 대한 환경 평가 절차와 초국가적인 환경 전략 틀을 도입하는 것에서 출발한다. 그리 고, 국별환경개요서(Country Environmental Review)와 경제 및 섹터분야의 전략 평가와 같은 투 입요소가 비환경분야의 투입요소들과 함께 CAS 작성을 위해 활용되는 것도 주요 절차 중의 하나이 다. 〈그림 4〉의 우측을 살펴보면 완성된 CAS 초안은 기초적인 유무상원조의 틀을 포함하는데 새로 운 SEA 활용 시스템에서 CAS 초안은 SEA 결과를 반영하여 수정된다. 이 단계에서 잠재적인 섹터 환경평가 또는 프로그램 환경평가를 수행할지 여부를 판단할 수 있다. 최종 CAS는 국별 실행계획 을 위한 틀을 제공할 것이며 이 단계에선 2 개의 환경 평가 단계가 남아 있다. 하나는 프로그램 차관 등이 잘 정의되지 않은 상황에서 국별 실행계획의 다음 단계로 섹터 환경평가와 프로그램 환경평가 를 수행하는 것이며 다른 하나는 국별환경계획에서 명시된 특정 프로젝트와 관련된 기타 이슈들에 대해 환경 평가를 수행하는 것이다. 


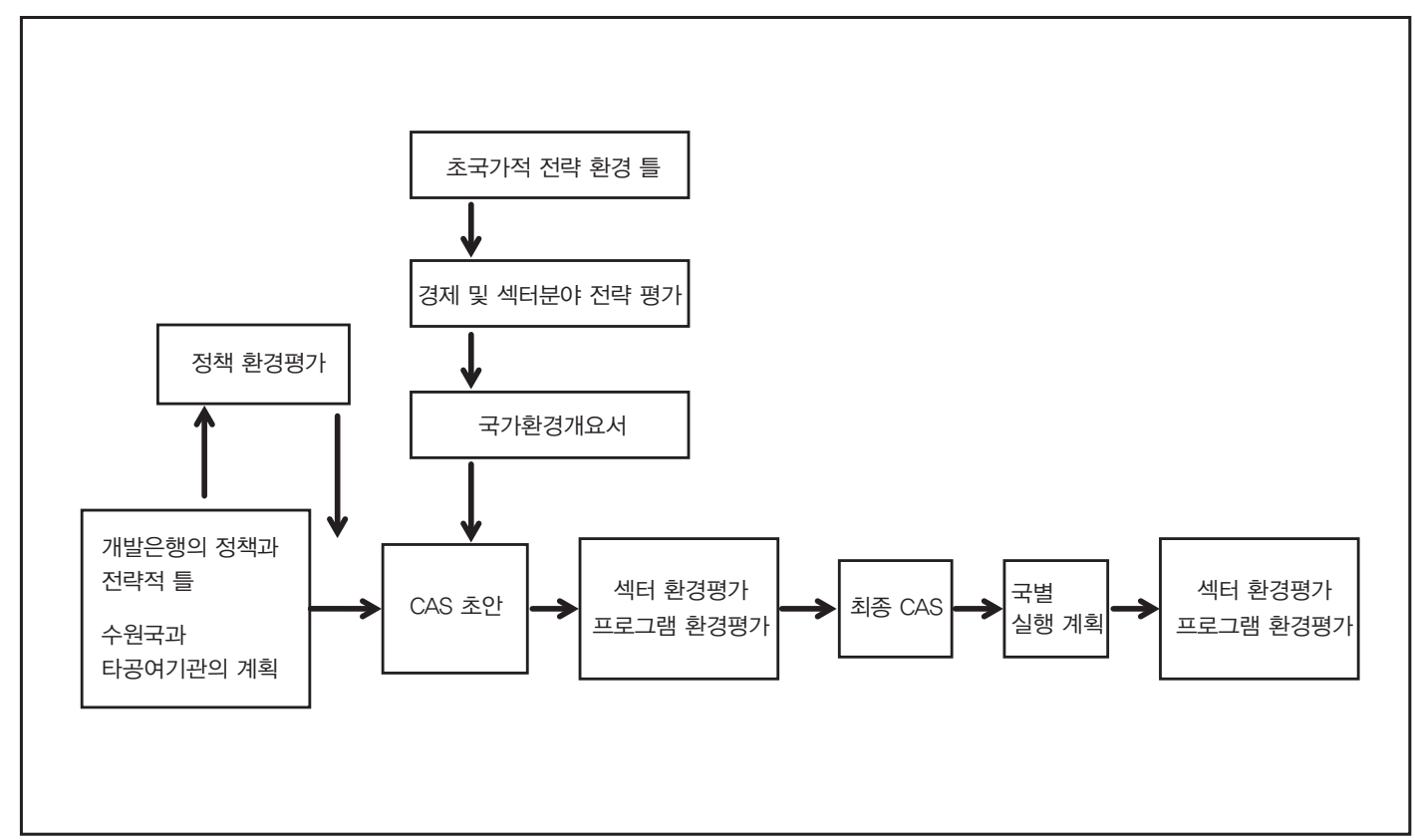

기존의 $\mathrm{MDB}$ 의 사업 수행방식에 비추어 그들의 제안에서 가장 중요한 변화는 $\mathrm{CAS}$ 수립과정에서 단계적으로 수정을 할 수 있다는 것으로, 이와 같이 CAS 수립 과정을 변화시키는 것은 이 단계에서 국가전략, 섹터 개발 프로그램, 프로그램형 차관 등이 결정되는 것을 기억한다면 포괄적인 SEA 시 스템을 $\mathrm{MDB}$ 의 국제협력 활동에 통합시키기 위한 매우 기본적인 사전필수요소라고 할 수 있다.

\section{SEA의 평가}

$\mathrm{SEA}$ 가 얼마나 잘 수행되고 있는지 품질에 대한 관리가 반드시 병행되어야겠지만 SEA의 성공 여부 를 측정하는 가장 중요한 지표는 장기적으로 지속가능성을 유지하면서 이루어낸 개발협력의 결과 라는 것에 주목해야한다. SEA를 검토할 때는 정보의 질, 이해관계자의 참여도, SEA의 목적, 계획 된 향후 조치들 및 제약점 등이 주요 확인 사항이며 특히 평가자들은 SEA를 활용한 개발의 결과에 집중하여 $\mathrm{SEA}$ 수행 중 설정된 가정의 정확도와 그것이 $\mathrm{PPP}$ 와 실행 과정, 개발 목적 등에 미치는 영향, 그리고 역량 강화를 위한 활동의 결과들을 주요 평가 항목으로 포함시켜야 한다.

International Association for Impact Assessment(IAIA)는 효과적인 SEA를 수립하고 이미 수

3) 출처 : Annandale 등, 2001 
행한 SEA의 효과성을 평가하기 위한 지침을 제공할 목적으로 SEA 수행 평가기준을 발표하였다. 3 년이 넘는 토의 기간을 거쳐 2001년에 IAIA 이사회에 의해 승인된 지침은 〈표 2〉에서 보여준 것처 럼 6 개의 항목으로 구성되어 있으며 세계은행은 여기에 '영향력' 항목을 추가하여 세계은행의 SEA 관련 직원들이 참조하도록 하였다(IAIA, 2002; Ahmed 등, 2005).

〈표 2〉성공적인 SEA의 구성요소

\begin{tabular}{|c|l|}
\hline 통합성 & $\begin{array}{l}\text { 사회적, 경제적, 생물물리학적 측면의 상호연관성을 밝히고 환경분야 및 다른 관련된 섹터와 지역에 } \\
\text { 서 PPP에 통합 }\end{array}$ \\
\hline 지속가능성 & 사용할 수 있는 지속가능한 개발의 대안을 제시 \\
\hline 집중성 & 주요 이슈에 집중하고 의사 결정과정에 신뢰할 수 있는 유용한 정보를 제공 \\
\hline 신뢰성 & $\begin{array}{l}\text { 담당기관에서 SEA 과정에 책임의식을 가지고 전문적이며 공평하게 SEA가 수행될 수 있도록 주도적 } \\
\text { 으로 활동 }\end{array}$ \\
\hline 참여도 & 이해관계자들에게 정보 제공 및 의견 수렴 \\
\hline 반복성 & 의사결정에 영향을 미칠 수 있도록 정보의 초기 접근성 확보 \\
\hline 영향력 & 미래의 정책 결정에 영향을 미치도록 노력 \\
\hline
\end{tabular}

성공적인 $\mathrm{SEA}$ 는 계획자, 정책결정자, 그리고 영향받는 일반인들에게 전략적 결정의 지속가능성에 대한 정보를 제공하고 최상의 대안을 찾는 것을 촉진하며 정책 결정과정에서 민주적 의사결정이 이 루어질 수 있도록 해준다. 이러한 과정을 통해 결정에 대한 신뢰도가 상승하며 향후 프로젝트 레벨 에서 환경평가를 실시할 때 비용과 시간측면에서 더욱 효율적인 방식으로 진행될 수 있다.

$\mathrm{DAC}$ 또한 성공적인 $\mathrm{SEA}$ 수행을 위해 여러 활동을 추진하여 왔는데 원조효과성을 높이기 위한 가 장 주요한 활동 중의 하나인 동료심사에서도 SEA를 심사항목으로 추가하였다. 2009년에서 2010 년의 기간 동안 동료심사를 위한 기초로 사용될 'DAC 동료심사 가이드’는 2008년 10월 16일 DAC 회의에서 개정본이 승인되었는데 이 개정본에 의하면 심사대상국은 DAC 심사위원과 협의하여 "농 업, 고식량가와 공여국 대응” 또는 “환경과 기후변화” 중에 하나를 선택하여 심사를 받을 수 있으 며 “환경과 기후변화”를 선택하였을 때 SEA에 대한 심사를 받게 된다.

세부심사항목을 살펴보면 공여기관의 본부에 대한 심사항목으로 $\mathrm{SEA}$ 를 필수적으로 요구하였는 지 그리고 이에 대한 지침이 있는지 그렇다면 이것들은 기후변화를 고려하는지 여부, 직접 예산 지 원이나 섹터 예산 지원과 같은 프로그램적 방법과 관련하여 기후변화를 체계적으로 고려하기 위해 $\mathrm{SEA}$ 가 사용되고 있는지가 제시되었다. 개발협력의 사업현장에서도 프로그램적 지원 방법과 관련 하여 SEA가 기후변화를 체계적으로 고려하기 위해 사용되고 있는지 그리고 그 실행이 어떻게 모니 터되고 평가되고 있는지 심사하도록 하고 있다(OECD, 2008). 


\section{4. 우리의 경험}

우리나라에서 SEA는 사업 추진단계에서 시행되는 환경영향평가제도의 한계를 극복하기 위하여 1993년에 개발사업의 추진에 영향을 미칠 수 있는 행정계획 수립단계에서 환경영향을 검토하는 사 전환경성검토제도가 그 출발점이라고 할 수 있다. 사전환경성검토제도는 총리훈령으로 출발하였으 며 1999년 12월에 환경정책기본법의 개정을 통해 법정제도로 정착하게 되었고 2000년 8월 동법 시행령을 개정하여 법제화됨에 따라 각종 개발사업 시행 및 행정계획 수립 시 보다 면밀하게 환경 에 대한 평가를 실시할 수 있는 기반이 마련되었다.

이러한 법제화는 사전예방적 의사 결정 수단으로서 동 제도가 제 역할을 다 할 수 있도록 하기 위한 것이었으나 법제적 측면에서 정책 또는 계획이 대부분 평가대상에서 제외되었으며 이해관계자들의 의견 수렴상의 문제 등의 이유로 선계획-후개발의 체계 구축이라는 본래 의도가 실질적으로 구현 되지 않고 있다는 비판을 받아 왔다(오규식, 2006; 유헌석, 2006).

사회적인 요구의 증가로 $\mathrm{SEA}$ 의 도입, 시행이 결정되었는데 정부는 기존의 사전환경성검토제도의 개선을 통하여 SEA를 실시토록 방향을 설정하였다(유헌석, 2006). 이에 관련법인 '환경정책기본 법'에 대한 개정안이 마련되었으며 동 법 개정안은 2006년 6월부터 전면적으로 시행되었다. SEA 의 대상이 되는 계획을 수립, 입안하는 부처에서의 반발은 예상외로 강력한 것이었으며 결국 2004 년말 자체훈령으로 전략환경평가제도를 도입한 건설교통부는 별도로 전략환경평가대상 행정계획 을 정하였다. 이에 사전환경성검토대상 행정계획이 종전 38 개에서 83 개로 확대되었으며 건교부 것 을 합하면 그 대상이 100 개가 넘게 되었다. 다시 말하면 우리나라의 경우 주요 행정 계획에 대하여 $\mathrm{SEA}$ 를 실시하고 있다고 할 수 있다.

그러나 개선된 사전환경성검토의 평가범위가 여전히 정식 SEA에 비해 협소하다는 문제점이 전문 가들에 의해 지적되고 있다. 앞에서 설명하였듯이 $\mathrm{SEA}$ 는 환경적 고려를 $\mathrm{PPP}$ 에 통합하는 수단이 다. 그렇지만 우리나라의 SEA는 PPP 중 개발계획 즉 계획 분야만을 평가대상으로 정하였으며 정 책의 수립과정에는 침묵하고 있다. 선진국에서도 논의단계에 있는 것으로 간주할 수 있는 정책에 대한 환경평가를 제외하고라도 프로그램 평가는 아예 논의조차 되지 않고 있다(정병길, 2009).

특히 SEA에 바탕을 둔 사전환경성검토가 최근까지도 본격적으로 이루어지고 있지 않다는 것은 우 리사회에서 관련 기반 여건이 아직 조성되지 않았음을 나타낸다. SEA는 장기적이며 종합적인 관점 에서 평가를 수행해야 하기 때문에 고도의 전문성과 분석능력을 갖추어야 평가결과의 구체성과 신 빙성을 담보할 수 있다. 복잡한 환경인자간의 인과관계, 환경용량과 누적영향이 고려되어야 하는 등 이전의 단편적인 접근방법으로는 부족하기 때문에 평가체계와 방법에 대한 충분한 연구와 분석 
이 진행되고, 그에 따른 결과물로 구체적인 방법 등을 제시하는 지침서가 마련되며 특히 전문평가 인력이 확보되어야 한다(정병길, 2009)

이처럼 아직 우리나라 내부에서도 성공적인 SEA 수행을 위한 역량 및 경험이 축적되어 있지 않기 에 우리의 개발협력사업 추진과 관련하여 SEA가 활성화되기는 아직은 시기상조이며 또한 국제사 회의 개발협력분야에서 $\mathrm{SEA}$ 에 대한 논의를 주도적으로 이끌기는 어려울 것으로 판단된다. 그렇 다고 두손 놓고 있을 수는 없는 일이며 $\mathrm{OECD}$ 의 $\mathrm{SEA}$ 가이던스가 제시한 것처럼 역량강화를 통해 $\mathrm{SEA}$ 의 가치와 중요성에 대한 인식부족을 타계하고 SEA의 실행에 대한 지식부족을 만회해 나가야 겠다.

\section{III. 환경과 개발 네트워크의 SEA 관련 활동현황}

환경과 개발 네트워크는 개발도상국에서 환경 및 기후변화를 개발의 모든 측면에 통합하는 것을 촉 진하기 위해 $\mathrm{DAC}$ 회원국들의 경험을 공유하고 회원국들의 노력을 모니터하기 위한 장이다. ${ }^{4)}$ 환경 과 개발 네트워크의 주임무는 (1) $\mathrm{OECD}$ 의 범섹터적 접근의 맥락에서 지속가능한 발전을 위한 응축 된 접근법을 형성하는 것에 기여하고 (2) 환경과 지속가능한 개발을 지지하기 위해 개발협력을 위 한 세분화된 지침을 작성하며 (3) 환경이슈를 개발협력에 통합하는 것과 관련된 경험과 성공스토리 를 확산하기 위한 정책적인 장을 회원국들에게 제공하는 것이다.

\section{1. 환경과 개발 네트워크의 구성}

환경과 개발 네트워크는 DAC 회원국을 주축으로 세계은행 및 UN과 같은 다자개발기구의 환경과 기후변화 분야의 전문가들로 구성되어 있으며 무엇보다 수원국의 대표들, 지역 개발은행, 그리고 $\mathrm{NGO}$ 및 연구기관들도 참여하여 $\mathrm{OECD}$ 내에서 개발과 환경 이슈에 대한 논의를 주도하고 있다. 개 발과 환경 관련된 정책 결정의 밑바탕을 제공하고 있는 작업반은 현재〈표 3 〉에서 제시한 것처럼 모두 4개로 이 중에는 SEA를 위한 작업반도 포함되어 있다.

$\mathrm{SEA}$ 를 위한 작업반은 2004년에 설립되었다. 작업반의 구성원은 환경과 개발 네트워크 안에서 탄력적으로 이루어지며 SEA 분야의 세계적인 전문가들도 참여한다. 작업반 설립 당시의 목적은 2006년에 발간된 ‘SEA 지침’을 작성하는 것이었으며, 그 후에는 SEA에 대한 경험 교류와 관련 자

4) www.oecd.org/dac/environment 
료 공유 등을 지속적으로 추진하고 있다. 본 작업반의 협력 기관은 $\mathrm{DFID}, \mathrm{GTZ}, \mathrm{Sida}$ 와 같은 선 진공여국의 원조기관과 $\mathrm{ADB}$ 등 지역 개발은행, $\mathrm{UNDP}$ 및 $\mathrm{UNEP}$ 와 같은 $\mathrm{UN}$ 산하기구, 그리고 WWF와 같은 환경단체 등이다.

\section{〈표 3〉 2009-2010의 환경과 개발 네트워크 작업반 리스트}

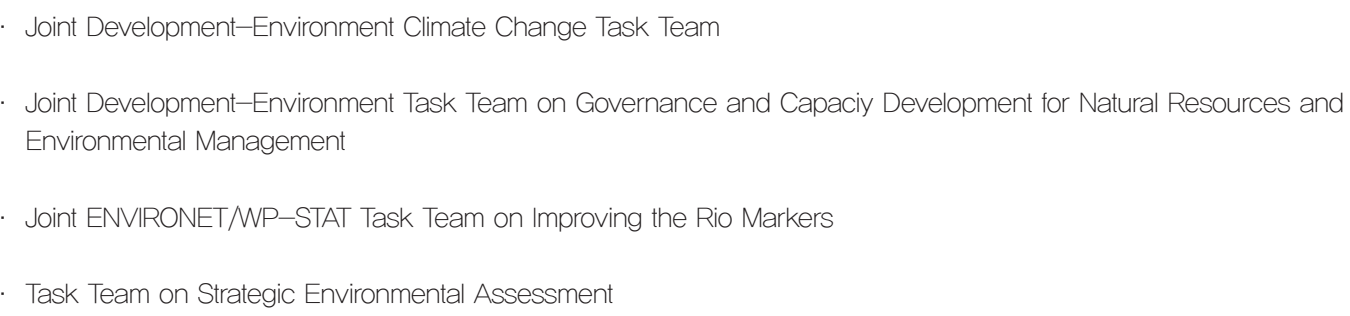

\section{2. 환경과 개발 네트워크의 주요 임무}

녹색성장의 성공적인 추진을 통한 MDGs 달성을 추구하는 환경과 개발 네트워크의 여러 업무들은 아래와 같은 분야를 중심으로 구성되어 있다.

(1) 기후변화: 기후변화 적응과 완화를 개발협력에 통합하는 방안과 기후변화 대응을 위한 전지 구적 노력이 빈곤감소에도 기여할 수 있도록 노력

(2) 역량 강화: 자원 및 환경 관리를 위한 역량 강화

(3) 환경 평가: ‘SEA 적용을 위한 정책 지침’의 실행 정도를 모니터하고 국가 수준에서 조화된 접근 방식을 지원

(4) 리우협약의 구현: 리우협약의 달성을 지원하는 원조의 흐름을 모니터하기 위한 보고 및 통계 방식의 향상

환경과 개발 네트워크의 홈페이지에서는 위의 네번째 항목 대신 'OECD 녹색성장 전략에의 기여'가 네 개의 주요 업무 중의 하나로 제시되어 있다. 


\section{3. 환경과 개발 네트워크의 SEA 분야 주요 활동}

지금까지의 환경과 개발 네트워크의 활동 중 SEA와 관련된 주요 활동 및 성과는 아래와 같다 (OECD, 2010).

\section{1) 전략적 환경평가 적용 지침}

동 지침은 영국과 UNDP가 주도하는 SEA 작업반에 의해 작성되었으며 'DAC Guidelines and Reference Series'의 한 부분으로 출간되었고 2006년 DAC에 의해 승인되었다. International Association for Impact Assessment는 이 지침의 우수성과 환경평가 부분에 미치는 영향력을 고 려하여 2006년 해당 작업반에게 기관상을 수여하였다.

\section{2) SEA에 대한 인식제고}

$\mathrm{SEA}$ 작업반은 SEA에 대한 인식제고를 위해서도 꾸준히 노력해오고 있다. 개발협력분야에서 SEA 의 실행을 촉진하기 위해 전단지, 안내 책자, CD-Rom 형태의 보고서, 파워포인트를 이용한 발표 자료 등을 제작하여 왔으며, GTZ에 의뢰하여 SEA 훈련 과정도 개발하였다. 이러한 훈련 프로그램 은 알제리, 모로코, 인도네시아, 중국, 베트남 등지에서 완성도와 실용성이 시험되었다. 특히 작업 반은 공여국과 수원국 정부의 SEA에 대한 인식제고를 위해 'SEA 로드쇼'를 시작하였으며 2008년 잠비아에서는 워크샵을 실시하기도 하였다.

\section{3) SEA와 기후변화 적응에 대한 Advisory Note 발간}

‘SEA 적용 지침’은 여러 범위의 PPP에서 SEA를 활용할 때의 틀, 단계 및 원칙을 훌륭하게 제공하 고 있지만 개발협력분야에서 여러 이슈들이 추가로 중요해지면서 그 한계점이 드러나기 시작하였 다. 즉 $\mathrm{SEA}$ 적용 시에 이러한 주요 이슈들을 고려해야만 하는 상황에서 더 자세한 지침이 존재하여 야하는 필요성이 인식되기 시작하였는데 이에 환경과 개발 네트워크는 적용지침을 한 단계 개선시 키기 위해 보완지침을 시리즈로 발간하고 있다. 현재까지 재난 위험 감소, 기후변화, 갈등 후 복구, 생태계 서비스에 대한 주제로 발간되었다.

기후변화에 대한 보완지침의 의도는 (1)어떻게 SEA가 기후변화와 관련된 위험과 기회를 전략적 계획에 통합하기 위한 틀을 제공할 수 있는지 보여주고 (2) PPP를 계획하고 준비하는 관계자들에 게 기후변화를 $\mathrm{PPP}$ 에 통합할 수 있도록 방향을 제시하는 것이다. 기후변화로 인해 발생하는 여 러 악영향에 대한 증거와 위험에 대한 인식이 증가하면서 $\mathrm{PPP}$ 가 기후변화에 대한 고려를 포함해 야하는 경우가 점점 증가하고 있다. $\mathrm{SEA}$ 를 사용하여 $\mathrm{PPP}$ 수립과정에 기후변화를 통합시키는 것 
은 변하는 기후상황에서 좀 더 지속가능하며 보다 발전된 개발을 가져올 수 있는 여러 정보들을 분석하고 이러한 분석과 증거자료에 기초한 $\mathrm{PPP}$ 를 수립하는 것이다. OECD는 "Guidelines on Integrating Climate Change Adaptation into Development Cooperation”에서 기후변화 적응 렌즈(adaptation lens)라는 용어를 새롭게 제시하며 기후변화를 개발협력 과정에 통합하여야 함을 강조하였다.

기후변화 보완지침에서 제시하는 단계는 아래 4개로 구성되어 있다(OECD ENVIRONET, 2008)

· 1 단계 : $\mathrm{PPP}$ 의 내용 수립

$\mathrm{PPP}$ 가 어떤 내용을 담고 있느냐에 따라 $\mathrm{SEA}$ 과정에서 기후변화 적응을 고려해야 하는지 말아 야 할지가 결정되는데 농업, 수자원 등과 같은 분야는 그 연결고리가 명확하나 많은 경우에는 명확하지 않다. Advisory는 기후변화 적응과의 잠재적 연결성을 찾기위해 고려해야할 사항 등 을 표로 제시하였다. 이 과정에서 이해관계자들이 참여할 수 있는 투명한 정책결정 과정이 필 수이다.

· 2 단계 : SEA의 실행

$\mathrm{SEA}$ 의 실행은 $\mathrm{SEA}$ 관련 작업들의 범위를 정하고 기준선이 될 수 있는 사전 데이터를 수집하 는 것에서 출발하며 진행과정을 통해 기회를 증가시키고 위험을 줄일 수 있는 방안을 발굴하여 야한다. Advisory는 SEA 실행과정에서 위에서 제시한 범위정하기, 기초자료수집, 기회증가와 위험감소 방안, 대안 발굴 4개에서 고려해야 할 사항들을 상세히 제시하였다.

· 3 단계 : 정책결정자에게 정보전달 및 영향끼치기

$\mathrm{SEA}$ 결과를 정책결정자에게 제시하는 것은 SEA 수행 과정에서 매우 중요한 단계이다. 정책결 정자들이 기후변화를 SEA 과정에 통합하는 것에 소홀하게 되는 것은 이해관계자들과의 충분하 지 못한 사전협의, 기후변화에 대한 지식 또는 인식부족, 그리고 무엇보다 정치적 의지 부족이 원인일 수 있다.

· 4단계 : 모니터링과 평가

기후변화 적응 방안을 포함한 $\mathrm{SEA}$ 보고서가 결론지은 추천사항을 $\mathrm{PPP}$ 의 모니터링과 평가에 포함시켜야한다. 그리고 SEA의 모든 단계에서 주류화되어야할 이슈인 성평등 문제가 어떻게 기후변화 적응 관련하여서도 고려되어야 하는지 간략히 제시하였다. 


\section{SEA 관련 환경과 개발 네트워크의 활동 계획}

2010년 SEA와 관련된 환경과 개발 네트워크의 계획은 DAC/EPOC 장관급 회의의 후속조치를 위 한 작업들 외에 (1) SEA의 활성화 (2) 빈곤과 환경의 연결고리 파악 (3) 리우협약에 해당하는 지 원활동의 보고 방식의 지속적 개선 (4) 생물다양성과 개발협력의 4 개 분야를 포함한다. 이 중 SEA 를 활성화하기 위해 $\mathrm{SEA}$ 의 질을 검토 및 평가할 수 있는 보편적인 방법론을 개발하는 것,새로운 Advisory Notes의 작성 등이 계획되어 있다.

환경과 개발 네트워크의 SEA 작업반은 캐나다의 CIDA가 그들의 SEA를 점검할 수 있도록 개발한 방법론을 기초로 표준적인 평가방법을 제안하고자 노력하고 있다. 새로운 Advisory Note는 수요에 바탕을 두고 진행될 것이며 현재 스웨덴의 주도로 바이오연료에 대한 Advisory Notes의 개발을 고 려 중이다. 


\section{IV. 결론}

지금까지 환경주류화를 위한 정책적 도구인 SEA에 대하여 주요 개념과 이슈 그리고 $\mathrm{OECD}$ 내에서 $\mathrm{SEA}$ 에 관한 논의를 주도적으로 이끌어가고 있는 환경과 개발 네트워크의 활동현황, 성과 및 계획 등을 고찰해 보았다. SEA는 지속가능성의 문제를 한 국가의 상위 의사결정 단계에 통합시킬 수 있 는 매우 가치있는 방법으로 SEA의 장점 중의 하나는 상황에 맞게 절차 등을 탄력적으로 적용할 수 있다는 것이며 의사결정자들이 유용하게 활용할 수 있게 점차 진화하고 있다. 따라서 SEA를 사용 할 때는 SEA의 목적 및 적용 대상과 관련된 여러 맥락을 정의하고 접근 방식을 상황에 맞게 조정하 는 것이 필요하다.

궁극적으로 $\mathrm{SEA}$ 는 지속가능한 $\mathrm{PPP}$ 의 디자인을 촉진하기 위한 의도를 가지고 있기에 천년개발목 표의 일곱 번째 목표 ‘지속가능한 환경 보전’과 그 아래 아홉번째 세부목표인 '지속가능한 개발 원 칙을 각 개발국가의 정책과 프로그램의 기본으로 삼고 환경자원의 손실을 보전'의 달성에 효과적으 로 기여할 수 있다. 본문에서도 설명하였듯이 유럽 등에서 양자협력에 SEA를 활용하게 된 것은 자 국 내에서의 경험 축적이 시발점이었기에 우리나라도 전문인력의 양성 및 SEA의 활성화가 뒷받침 되어야만 개발협력 과정에서 $\mathrm{SEA}$ 를 통한 환경의 주류화를 달성할 수 있을 것이다. $\mathrm{KOICA}$ 는 자체 적으로 환경주류화를 위한 몇몇 사전 작업들을 수행해왔으나 향후 본격적인 추진을 위해서는 국내 $\mathrm{SEA}$ 관련 기관과의 지속적인 교류로 앞으로 확보될 국내의 역량을 활용할 수 있도록 하고 선진원 조기관 등의 SEA 동향을 꾸준히 파악하고 그들의 성공사례를 분석하여 시행착오를 줄일 수 있는 방안들을 구축하는 것이 바람직하다고 하겠다. 


\section{참고 자료}

\section{1. 국내문헌}

박명지 (2009), KOICA 사업의 녹색화 방안, 한국국제협력단, 성남

유헌석 (2006), “전략환경평가제도의 이해”, 도시정보 2006.12월호(No.297), pp. $7-12$

오규식 (2006), “전략환경평가와 지속가능한 사회”, 도시정보 2006.12월호 (No.297), p.2

정병길 (2009), “우리나라 환경영향평가제도의 문제점 및 개선방안에 관한 소고 : 공학적 관점에서의 검토”, 공법학연구 제 10 권 제2호, pp. 327-346

\section{2. 국외문헌}

Ahmed, K., Mercier, J.R., and Verheem, R. (2005), “Strategic Environmental AssessmentConcept and Practice”, Environment Strategy Notes, No. 14, World Bank, Washington D.C.

Annandale, D. Bailey, J., Ouano, E., Evans, W., and King, P. (2001), “The Potential Role of Strategic Environmental Assessment in the Activities of Multi-lateral Development Banks", Environmental Impact Assessment Review 21, pp.407-429

Borysova, O. (2007), "Potential of Strategic Environmental Assessment as an Instrument for Sustainable Development of the Countries in Transition," Hull, R. N. et al.(eds.), Strategies to Enhance Environmental Security in Transition Countries, pp.117-126

Internaional Association for Impact Assessment (2002), "Strategic Environmental Assessment Performance Criteria”, Special Publication Series No.1

OECD (2005), The Paris Declaration on Aid Effectiveness, http://www.oecd.org/ dataoecd/11/41/34428351.pdf 
Partidario, M.R. (2006), “Strategic Environmental Assessment; Experience and good practices in strategic approaches to assist decision-making, Training Materials, IAIA'06 Pre-Conference Training, Staganver

OECD (2006), Applying Strategic Environmental Assessment: Good Practice Guidance for Development Co-operation, DAC Guidelines and Reference series, OECD, Paris.

OECD (2008), DAC Peer Review Content Guide, DCD/DAC(2008)46/REV2, OECD, Paris

OECD ENVIRONET (2008), Strategic Environmental Assessment and Adaptation to Climate Change, OECD, Paris

OECD (2010), DAC Network on Environment and Development Co-operation Overview of Ongoing Work 2010, DCD/DAC/ENV(2010)1, OECD, Paris 